\title{
O ESTATUTO SOCIAL DO PROFESSOR DA EDUCAÇÃO INFANTIL: IDENTIDADE, FORMAÇÃO E ESTÁGIO ${ }^{1}$
}

\section{THE SOCIAL STATUS OF PRESCHOOL TEACHERS: IDENTITY, TRAINING AND INTERNSHIP}

\section{Menissa Cícera Fernandes de Oliveira Bessa Carrijo²}

RESUMO: Este artigo discorre sobre a construção profissional do professor de educação infantil, envolvendo a discussão das origens em fazeres femininos expropriados de intencionalidade profissional, as políticas de formação e as instituições envolvidas nesse processo ao longo da história. A pesquisa tem desdobramentos na perspectiva qualitativa e usou, como instrumento metodológico, um questionário de avaliação do estágio e de autoavaliação dos acadêmicos com o intuito de perceber (ou não) suas resistências sobre o trabalho na creche e na pré-escola.Pode-se constatar que existem especificidades no trabalho do professor da educação infantil, contudo os currículos de pedagogia seguem privilegiando o trabalho com crianças maiores, além disso, os sujeitos da pesquisa mostraram palpáveis sinais de resistência em se tornarem docentes da educação infantil em virtude da construção sócio-histórica do perfil desse profissional.

PALAVRAS-CHAVE: professor, educação infantil, perfil, estágio, resistência.

ABSTRACT: This article discusses the professional construction of the preschool teacher, involving the discussion of its origins in female practices expropriated from professional intentionality, the training policies and the institutions involved in this process throughout history. The research has unfolded in the qualitative perspective and has used, as a methodological instrument, a questionnaire to assess students' internship and self-assessment with the aim of perceiving (or not) their resistance to work in daycare and in preschool. It was verified that there are specificities in the work of the preschool teacher, but pedagogical curricula continue to favor work with older children. In addition, the research subjects showed palpable signs of resistance in becoming teachers of early childhood education

\footnotetext{
${ }^{1} \mathrm{O}$ projeto de pesquisa do qual faz parte esta investigação tem como título "A formação do pedagogo em destaque: referências teórico-metodológicas e docência universitária", e foi registrado na Pró-Reitoria de Pesquisa da Universidade Federal do Tocantins (UFT) com o código PA10 \# 003/2013.

${ }^{2}$ Mestre em Educação, Professora do Curso de Pedagogia. Universidade Federal do Tocantins- UFT. PalmasTO-Brasil. bessacarrijo@uft.edu.br
}

Rev. Fac. Educ. (Univ. do Estado de Mato Grosso), Vol. 28, Ano 15, № 2 p. 15-36, jul./dez. 2017 (Epub Ahead of Print 8. out., 2017) 
due to the social and historical construction of the profile of this professional.

KEYWORDS: teacher, preschool education, profile, internship, resistance.

\section{Introdução}

Desde a década de 1990, a discussão sobre a formação de docentes para atuar na educação infantil tem-se revelado importante no campo educacional, sobretudo com a aprovação da Lei no 9.394/1996, ou Lei de Diretrizes e Bases da Educação Nacional (LDB) (BRASIL, 1996)³. As políticas públicas de preparação dos professores da educação básica - em que a educação infantil constitui a primeira etapa - avolumaram-se, tendo em vista que a LDB, no Artigo 62 , indica o ensino superior como ponto alto a se buscar para a capacitação de profissionais de educação que trabalham desde a creche.

Conforme Didonet (2014, p. 164), "ainda se está em busca de melhor definição do perfil profissional e de uma fonte de recursos que sustente um quadro de profissionais qualificados". Tal indefinição do perfil profissional da pessoa que trabalha em instituições com bebês, crianças bem pequenas e crianças pequenas ${ }^{4}$ é um vestígio da história da educação infantil no Brasil, que se desenvolveu de forma precária, até mesmo na preparação e no reconhecimento dos seus educadores. Para Pimenta e Lima (2004, p. 63), "a identidade vai sendo construída com as experiências e a história pessoal, no coletivo e na sociedade". No caso dos docentes ligados à educação infantil, o peso social é de pouca notoriedade e há um forte apelo das questões de gênero. A despeito dessa situação, intenta-se neste artigo discorrer sobre a construção histórica e social da identificação do profissional da primeira etapa, revelando os entremeios das instituições de formação e algumas políticas públicas envolvendo a universidade e a preparação específica do professor da educação infantil. A discussão culmina, intencionalmente, na disciplina de estágio supervisionado

\footnotetext{
${ }^{3}$ Há várias produções sobre a formação de professores da Educação Infantil envolvendo a compreensão do seu perfil, as orientações teórico-prática, metodológicas, cursos de formação e estágio: Araújo (2006), Barbosa (2011), Drumont (2014), Silveira (2015). Para Silveira (2015) os estudos ainda são pouco e a área carece de mais pesquisas sobre o tema nos cursos de pedagogia.

(Epub Ahead of Print 08 out.,2017)

${ }^{4} \mathrm{Na}$ busca de termos adequados para indicar as idades das crianças da educação infantil, usou-se como referência o documento Práticas cotidianas na educação infantil: bases para a reflexão sobre as orientações curriculares (BRASIL, 2009): bebês têm entre 0 e 18 meses; crianças bem pequenas têm entre 19 meses e 3 anos e 11 meses; crianças pequenas têm entre 4 anos e 6 anos e 11 meses; finalmente, crianças maiores têm entre 7 anos completos e 11 anos e 11 meses.
}

Rev. Fac. Educ. (Univ. do Estado de Mato Grosso), Vol. 28, Ano 15, № 2 p. 15-36, jul./dez. 2017 (Epub Ahead of Print 8. out., 2017) 
da educação infantil do curso de Pedagogia, por meio da qual capturaram-se sinais de relutância que os alunos desvelam nesse momento do processo de formação em que se tornam professores de crianças pequenas.

Este estudo faz parte do trabalho desenvolvido pelo grupo de pesquisa "Formação de professores: fundamentos e métodos do curso de Pedagogia da Universidade Federal do Tocantins (UFT), câmpus Palmas", e possibilita delimitar uma investigação sobre as especificidades da formação do educador infantil. A pesquisa tem desdobramentos na perspectiva qualitativa e usou, como instrumento metodológico, um questionário de avaliação do estágio e de autoavaliação dos acadêmicos, com o intuito de perceber (ou não) suas resistências sobre o trabalho na creche e na pré-escola. Para tanto, buscou-se nas respostas dos sujeitos da pesquisa, alunos do curso de Pedagogia da UFT/ Palmas durante cinco semestres letivos, a compreensão do ânimo ou relutância que eles têm sobre tornarem-se educadores infantis, assim como a contribuição da disciplina de estágio para sua formação.

\section{A profissionalização do educador infantil: história, indefinição do perfil e políticas públicas de formação}

Muito mais que simplesmente pensar nos tempos remotos do surgimento da educação infantil e do profissional para nela atuar, estudar sua história, demarcando suas origens e dando significado à sua trajetória, é desvendar o tempo presente e, então, buscar possíveis saltos para um futuro melhor. Faz-se imprescindível revelar as circunstâncias, situando aquilo que se foi, dando horizonte para um porvir, sem que se fique preso ao imediatismo que pode ser pouco esclarecedor, afinal "não existem, nas vozes que escutamos, ecos de vozes que emudeceram?" (BENJAMIN, 1987, p. 223).

O objeto da educação contextualizado, segundo Kuhlmann (1998, p. 17), é "elemento constitutivo da história da produção e reprodução da vida social". Dessa forma, os fatos sociais que levaram à criação das primeiras instituições voltadas para o atendimento de crianças entre zero e seis anos, tais como "demografia infantil, o trabalho feminino, as transformações familiares, novas representações sociais da infância, etc." (KUHLMANN, 1998, p. 17), são indicativos da constituição do perfil do professor trabalhador da educação infantil na atualidade.

A primeira instituição voltada para receber crianças de creche (até dois anos de idade) foi inaugurada em 1899 e estava ligada à fábrica de te-

Rev. Fac. Educ. (Univ. do Estado de Mato Grosso), Vol. 28, Ano 15, № 2 p. 15-36, jul./dez. 2017 (Epub Ahead of Print 8. out., 2017) 
cidos Corcovado no estado do Rio de Janeiro. Tal iniciativa, e outras que the sucederam, tinha os moldes das instituições francesas que atendiam bebês em creches e crianças maiores (entre três e seis anos de idade) em escolas maternais (KUHLMANN, 2003). Kuhlmann (2003, p. 479) relata que o trabaIho com as crianças era desenvolvido por mulheres sem qualificação alguma, mas as supervisoras eram professoras, "carreira escolar que se oferecia para a educação feminina, inclusive para as religiosas, responsáveis pelo trabalho em várias creches".

Nesse sentido, o trabalho feminino com crianças pequenas iniciou-se sem conotação profissional. Esse esvaziamento das características profissionais era resultado de um contexto em que a mulher não tinha espaço na esfera pública e em que a docência com crianças seria uma forma de conseguir ingressar em um trabalho fora da dinâmica doméstica, mas desempenhando as mesmas atividades de educação e cuidado do lar. Quanto a isso, Almeida (1998, p. 32) afirma: "era aceitável que as mulheres desempenhassem um trabalho, desde que este significasse cuidar de alguém. $O$ doar-se com nobreza e resignação, qualidades inerentes às mulheres, era premissa com a qual também se afinavam profissões como enfermeira ou parteira".

Micarello (2011, p. 216), ao analisar a história da constituição de professores da educação infantil, revela que, no início do século XX, as atividades desenvolvidas com crianças em instituições como creches e jardins de infância eram realizadas por mulheres, estas sem preparo, "especialmente em se tratando de crianças muito pequenas, que por sua condição de relativa imperícia demandam, de modo especial, cuidados físicos e relacionais". Por conta dessa lógica assistencialista, o empreendimento público inicial para a formação de docentes para a pré-escola foi tardio, acontecendo somente em 1974. Trata-se da Resolução ${ }^{\circ} 45$ do Conselho Federal de Educação (CFE) sobre a educação pré-escolar, que aprovou a habilitação no magistério no âmbito do segundo grau (MINISTÉRIO DA EDUCAÇÃO E CULTURA, 1979).

Cabe resgatar um pouco a história dos cursos de formação de professores para compreender como se chegou à Resolução $n^{\circ} 45$. 0 curso de Pedagogia já existia, assim como as demais licenciaturas, por força do Decreto $n^{\circ} 1.190$, de 1939. A organização desses cursos teve a marca do conhecido esquema $3+1$, que se resumia, basicamente, a estudos específicos no decorrer dos três anos iniciais e à formação em didática que habilitava um indivíduo a lecionar no último ano (SAVIANI, 2009). Contudo, o curso de Pedagogia formava professores para as chamadas escolas normais, que por sua vez preparavam docentes para a então nomeada escola primária. Com a 
aprovação da Lei $n^{\circ}$ 5.692/1971 (BRASIL, 1971), que fixava diretrizes e bases para o primeiro e segundo graus ${ }^{5}$, as escolas normais deixaram de existir e a formação de professores para o primeiro grau passou a ser uma habilitação de curso de segundo grau.

Segundo Saviani (2009, p. 147), “a habilitação [...] foi organizada em duas modalidades básicas: uma [...] de três anos (2.200 horas), [...] para lecionar até a $4^{\text {a }}$ série; e outra [...] de quatro anos (2.900 horas), habilitando ao magistério até a $6^{\text {a }}$ série do $1^{\circ}$ grau". No contexto pós-lei de 1971 , o curso de Pedagogia formava professores para o magistério de nível médio e especialistas em educação como diretores, supervisores e orientadores. Diante dessas mudanças na legislação do ensino e da necessidade de refletir sobre as especificidades da educação pré-escolar, o CFE passou a discutir como seria essa habilitação no âmbito do segundo grau. A conselheira Maria Terezinha Tourinho Saraiva propôs, por meio do Parecer $n^{\circ} 1.600 / 1975$ - que foi aceito -, que em um quarto ano do curso de magistério fossem oferecidos estudos adicionais voltados para a educação pré-escolar.

Pode-se concluir que existia uma preocupação específica do Ministério da Educação e Cultura (MEC) com o objeto da educação pré-escolar. Kramer (1995) contribui para o entendimento dessa vicissitude na proposta de atendimento e, consequentemente, de melhor preparo dos professores para trabalhar com crianças de quatro, cinco e seis anos de idade na época, posto que o governo federal já havia tomado a decisão de implantar uma educação compensatória na pré-escola, cujo objetivo era contribuir com o maior sucesso dos alunos nas séries iniciais do primeiro grau.

Maria Terezinha Saraiva declara:

[...] embora nos faltem dados, pelo próprio panorama do professorado brasileiro de 1 o grau, se pode afirmar, com grande dose de verdade, que pouquíssimos professores em exercício junto a pré-escolares possuem formação adequada, uma vez que os currículos dos antigos cursos normais (e mesmo superiores de modo geral), não enfatizam necessariamente a importância e a didática para atender crianças abaixo dos 7 anos. Isso é mais grave quando sabemos que, convenientemente assistidas, muito se pouparia, em tempo futuro, com reeducação psicomotora, de apoio ou supletiva. (MINISTÉRIO DA EDUCAÇÃO E CULTURA, 1979, p. 44-45).

${ }^{5}$ Nomenclatura dada com a Lei $n^{\circ} 5.692 / 1971$.

Rev. Fac. Educ. (Univ. do Estado de Mato Grosso), Vol. 28, Ano 15, № 2 p. 15-36, jul./dez. 2017 (Epub Ahead of Print 8. out., 2017) 
Era bem verdade que não havia conteúdo nos cursos de formação direcionados à educação de crianças pequenas, e ficou evidente na manifestação da relatora a proposta de educação compensatória expressa na iniciativa de suprir carências culturais de crianças pobres, uma vez que "faltariam a estas crianças, 'privadas culturalmente', determinados atributos, atitudes ou conteúdos que deveriam ser nelas incutidos" (KRAMER, 1995, p. 24). Esse assunto também foi discutido e aprovado na sessão de 2 de julho de 1974, que aprovou o Parecer $n^{\circ} 2.018$, quando o relator da Resolução $n^{\circ} 45$, Paulo Nathanael Pereira de Souza, aconselha que "se dê ênfase aos programas de emergência caracterizados como de 'educação compensatória' para a população de 6 e 5 anos ou menos [...]" (MINISTÉRIO DA EDUCAÇÃO E CULTURA, 1979, p. 28).

Cabe comentar que, simultaneamente a essas iniciativas na vertente compensatória, pensadores da educação de crianças pré-escolares como Froebel eram estudados no Brasil, sobretudo em escolas de ensino particular, e sustentavam propostas pedagógicas para atender à educação dos extratos sociais afortunados (OLIVEIRA, 2002). Segundo Barbosa (2011) como era nobre a mulher se dedicar ao cuidado, até mesmo mulheres de classe média e alta, com formação em magistério primário, se especializavam em conteúdos de abordagem da educação nova e liberal (Montessori, Decroly, Froebel, Dewey, dentre outros) para o trabalho com crianças pequenas da elite.

Para Saviani (2009, p. 147), esse desfecho do desaparecimento das escolas normais foi grave, uma vez que "o antigo curso normal cedeu lugar a uma habilitação de $2 \circ$ grau [...] configurando um quadro de precariedade bastante preocupante". Mas nos anos 1980 o curso de Pedagogia adotou a vertente de formação no princípio da docência, ou seja, a identidade do profissional formado estaria voltada para o perfil de professor, sobretudo aquele que atuaria na creche e pré-escola e nas séries iniciais do primeiro grau. Era um momento de renovação em sintonia com a Constituição Cidadã.

Assim, com o fim do período militar e a aprovação da atual LDB (BRASIL, 1996), esperava-se que os dilemas da formação para a agora chamada educação infantil (primeira etapa) e o Ensino Fundamental I pudessem ser mais bem trabalhados na educação superior no âmbito dos cursos de Pedagogia, mas "a LDB sinalizou uma política educacional tendente a efetuar um nivelamento por baixo" (SAVIANI, 2009, p. 148), sobretudo por admitir que institutos superiores oferecessem formação superior regular a custos baixos e em tempo reduzido. Além disso, a lei continuou admitindo a formação de nível médio para atuar nessas duas etapas (Artigo 62). Com base em Mészáros (2007, p. 117, grifo do autor), pode-se compreender que "os remédios educacionais formais, mesmo 
alguns dos maiores, e mesmo quando são sacramentados pela lei, podem ser completamente invertidos, desde que a lógica do capital permaneça intacta como enquadramento orientador da sociedade".

Sobre esses cursos de formação superior, Osteto (2000, p. 19) afirma que uma crítica a ser feita a seus currículos é a "[...] ênfase ao pólo 'educação' [...]", ou seja, os aspectos voltados para o cuidar e o brincar, a afetividade, a convivência coletiva e a cultura da infância têm menos espaço.

Valente (2015, p. 29) também ressalta os anos 1980 como período de luta por projetos pertinentes de formação e valorização da classe, dos quais muito se perdeu na década seguinte. Em 1997, o Decreto Presidencial n² 2.306 permitiu a flexibilização da formação de professores em institutos superiores, "mantendo-se a exigência da pesquisa e extensão apenas nas universidades". Já em 1999, o Decreto $n^{\circ} 3.276$ limitava a formação de professores para a educação infantil e séries iniciais do ensino fundamental somente a cursos normais superiores, o que foi barrado pelo Decreto $n^{\circ} 3.554 / 2000$ após diversas discussões e tensões, decreto esse que estabeleceu tal via como uma das possibilidades de preparação do professor, não a única.

Tem-se, assim, o perfil da política de formação que se instalou a partir da década de 1990, impressa pelas reformas neoliberais. Tal marca manteve-se em todos os setores, tendo como um de seus apontamentos o afastamento do Estado como provedor de bens sociais: "os intensos ventos vindos da Inglaterra, dos Estados Unidos, da Austrália e do Chile sopravam em sentido inverso aos direitos sociais [...]" (CURY, 2013, p. 205).

No que diz respeito especificamente à formação para a educação infantil, cabe aqui comentar o Programa de Formação Inicial para Professores em Exercício na Educação Infantil (Prolnfantil), iniciado em 2005. O Programa "é um curso semipresencial de formação em Ensino Médio, na modalidade Normal, emergencial, oferecido para professores em exercício nos sistemas municipais e estaduais de ensino" (MINISTÉRIO DA EDUCAÇÃO E CULTURA, 2010, p. 5). O que deu um sentido oposto a essa iniciativa de formação por meio do Prolnfantil e de cursos como o normal superior foi a aprovação das diretrizes nacionais para o curso de graduação em Pedagogia, cujo Artigo $2^{\circ}$ assim orienta: "As Diretrizes Curriculares para o curso de Pedagogia aplicamse à formação inicial para o exercício da docência na Educação Infantil e nos anos iniciais do Ensino Fundamental" (CONSELHO NACIONAL DE EDUCAÇÃO, 2006). Essas diretrizes criaram um marco conceitual importante sobre a preparação de docentes para a primeira etapa ao demarcar seu lugar no curso de Pedagogia, sendo tal curso instigado na busca de uma formação profissional

Rev. Fac. Educ. (Univ. do Estado de Mato Grosso), Vol. 28, Ano 15, № 2 p. 15-36, jul./dez. 2017 (Epub Ahead of Print 8. out., 2017) 
teórico-prática pertinente para o atendimento educacional da criança de pouca idade, incluindo o estágio supervisionado como componente curricular também para a educação infantil.

Apesar dessa importante política de formação que imprimiu um enaltecimento ao trabalho docente na creche e na pré-escola, segundo Leite Filho e Nunes (2013, p. 84), "há municípios que contratam profissionais sem qualificação para o exercício da função docente. Muitos são tratados, não como professores, mas como educadores, auxiliares, estimuladores ou agentes, entre outras denominações". Compreende-se que essa prática se efetiva diante dos problemas orçamentários para a manutenção da educação infantil e da pouca valorização do trabalho que se faz com a primeira infância em espaços institucionalizados, quer dizer, muitos gestores municipais acreditam que, para tutelar (limpar, alimentar e guardar) e brincar com crianças pequenas, não é necessário ter curso superior.

A lógica da institucionalização da criança pequena segue na tônica do capital que dita as formas de fazer educação para atender aos interesses dominantes. Mészáros (2007, p. 109, grifo do autor), ao discorrer sobre o impacto do capital na educação, afirma que as reformas educativas se prestam tão somente "para remediar os piores efeitos da ordem reprodutiva capitalistaestabelecida sem, contudo, eliminar os seus fundamentos causais antagónicos profundamenteenraizados". Diante disso é pertinente questionar: em que medida o fato de a formação do educador infantil estar situada no curso de Pedagogia tem contribuído para a melhor qualificação e valorização desse profissional?

Para Kishimoto (2011, p. 108), a formação de professores para a primeira infância em universidades enfrenta muitos obstáculos, pois a "tradição universitária tem reproduzido práticas em que professores se organizam em campos disciplinares, criam-se tradições, feudos, dificultando as reformas". Vê-se nisso uma significativa desarmonia entre a forma como a maioria das universidades organiza seu trabalho nos cursos de professores e as reais necessidades da escola infantil - da criança que ela recebe e do currículo que deve atendê-la. "A criança pequena aprende em contato com o amplo ambiente educativo que a cerca, que não pode ser organizado de forma disciplinar" (KISHIMOTO, 2011, p. 108).

É certo que os cursos de Pedagogia existentes no país têm tradição, em sua maioria, na formação de docentes para desempenhar suas funções nas séries iniciais do ensino fundamental com crianças maiores, assim como mostrou o breve esboço das instituições de formação de professores. Esse fato e a própria aplicação de uma educação compensatória para a pré-escola 
contribuíram para que a organização do trabalho com crianças pequenas tenha se tornado um reflexo do ensino fundamental, e "essa filiação inadequada cristalizou práticas conhecidas como a 'escolarização' na educação infantil" (KISHIMOTO, 2011, p. 107).

Portanto, cabe ao curso de Pedagogia compreender que a identidade do professor de educação infantil é diferente da dos profissionais habilitados para ser regentes nas turmas de crianças maiores. Oliveira-Formosinho (2011, p. 138), ao estudar o perfil do educador para atuar na primeira etapa, afirma que "a profissionalidade docente das educadoras é baseada numa rede de interacções alargadas". Diferentemente dos demais profissionais da educação básica, o educador infantil deverá ser capaz de realizar a difícil tarefa de educar e cuidar sob a perspectiva integrada, ou seja, de conceber a capacidade e competência sociopsicológica infantil para aprender, o que exigirá do professor a criação de um ambiente de convivências e experiências significativas. Contudo, o professor deverá ser sensível à vulnerabilidade do bebê, da criança bem pequena e da criança pequena, o que solicita a manutenção de seu bem-estar, segurança, higiene e saúde. Para Oliveira-Formosinho (2011), a globalidade da criança exige o alargamento das funções do educador, e as delimitações de seu trabalho acabam se tornando pouco definidas.

Além disso, esse professor da primeira infância deve ser capaz de se relacionar com um grande conjunto de pessoas ligadas à criança: pais, auxiliares, professores de áreas (arte, música, educador físico) e psicólogos, dentre outras. Isso porque a criança da educação infantil reúne em torno de si um grupo maior de profissionais e de áreas de atuação associadas aos sistemas de ensino; há, por exemplo, o envolvimento do pessoal da assistência social, o que demanda do professor o estabelecimento de muitas interações no sentido de integrar ações para a prestação de um bom serviço aos pequeninos (OLIVEIRA-FORMOSINHO, 2011).

Diante desse contexto de atuação, é inegável uma capacitação consistente do professor de educação infantil. Em que pese a importância de se ter profissionais bem qualificados para desenvolver atividades de educação e cuidado nas instituições infantis, o fato é que ainda hoje o Brasil tem um grande número de pessoas atuando sem formação e até mesmo profissionais titulados são desvalorizados, tendo em vista a construção social e histórica em que foi forjada essa profissionalização. Kramer (2011, p. 124) analisa essa situação: "dentre as questões e tensões específicas de natureza sociocultural com que nos defrontamos na área, [...] me parece fundamental: a nossa condição de mulheres". Os estudos de Kramer apontam que a prática com crianças na

Rev. Fac. Educ. (Univ. do Estado de Mato Grosso), Vol. 28, Ano 15, № 2 p. 15-36, jul./dez. 2017 (Epub Ahead of Print 8. out., 2017) 
educação infantil continua sendo desempenhada, predominantemente, pelo sexo feminino, e que as características de fazeres domésticos e sem tributos profissionais perpetuam-se na percepção que a sociedade tem sobre essa atividade.

Quanto à valorização e iniciativa de melhor formação dos professores, tem-se a recente Resolução $n^{\circ} 2$, de $1^{\circ}$ de julho de 2015, que define as diretrizes curriculares nacionais (DCNs) para a formação em nível superior (cursos de licenciatura, cursos de formação pedagógica para graduandos e cursos de segunda licenciatura) e para a formação continuada (CONSELHO NACIONAL DE EDUCAÇÃO, 2015). Para Dourado (2016, p. 29), "as DCN aprovadas e homologadas pelo MEC avançam na direção de maior organicidade para as políticas e gestão da formação inicial e continuada dos profissionais do magistério da educação básica". As novas DCNs têm como princípios norteadores: "[...] a) sólida formação teórica e interdisciplinar; b) unidade teoria-prática; c) trabalho coletivo e interdisciplinar; d) compromisso social e valorização do profissional da educação; e) gestão democrática; f) avaliação e regulação dos cursos de formação" (CONSELHO NACIONAL DE EDUCAÇÃO, 2015, p. 2). Além disso, a Resolução $n^{\circ} 2$ define, no parágrafo quarto do Artigo $3^{\circ}$, quem é o profissional da educação básica - incluindo o professor da educação infantil -, colocando -o, nessa lógica, em igualdade com os demais professores na formação e na importância de seu trabalho.

Os profissionais do magistério da educação básica compreendem aqueles que exercem atividades de docência e demais atividades pedagógicas, incluindo a gestão educacional dos sistemas de ensino e das unidades escolares de educação básica, nas diversas etapas e modalidades de educação (educação infantil, ensino fundamental, ensino médio, educação de jovens e adultos, educação especial, educação profissional e técnica de nível médio, educação escolar indígena, educação do campo, educação escolar quilombola e educação a distância), e possuem a formação mínima exigida pela legislação federal das Diretrizes e Bases da Educação Nacional. (CONSELHO NACIONAL DE EDUCAÇÃO, 2015, p. 4).

Talvez com essas novas diretrizes para a formação docente seja possível encontrar modos mais fecundos para a constituição do curso de Pedagogia e das demais licenciaturas para toda a educação básica. Na análise de Saviani (2009), ainda hoje o curso de Pedagogia não encontrou um caminho profícuo 
diante dos problemas de capacitação de pessoas que possam enfrentar os múltiplos desafios da educação básica do país, dentre eles, pode-se afirmar, a atenção educativa para crianças da creche e da pré-escola.

\section{Estágio e formação de professores da educação infantil: construindo caminhos}

Como já se viu, a formação universitária de professores constitui algo complexo e, no caso dos professores para a primeira infância, existem limitações. Dentre as dificuldades há algumas de ordem curricular, o que tem frequentemente obstaculizado uma preparação mais adequada do professor da educação infantil. Na tentativa de sanar essas dificuldades no que diz respeito ao currículo, um ganho significativo veio com as DCNs para o curso de graduação em Pedagogia (CONSELHO NACIONAL DE EDUCAÇÃO, 2006), que introduziu o estágio para a educação infantil.

Pimenta e Lima (2004, p. 111) indicam o estágio como uma excelente oportunidade de os alunos aproximarem-se da realidade em que poderão atuar, isto é, "aprender a profissão docente no decorrer do estágio supõe estar atento às particularidades e às interfaces da realidade escolar em sua contextualização na sociedade". Dessa forma, a organização dos planos para a oferta de estágio deve ir além das observações e regências tradicionais, adotando uma proposta de investigação cuja intencionalidade é superar a dicotomia teoria/ prática (PIMENTA; LIMA, 2004).

Para essas modificações importa, essencialmente, que a disciplina de estágio seja compreendida como um significativo componente curricular no curso de formação. Assim, no que concerne a orientações legais para a definição do estágio, a Lei Federal $n^{\circ}$ 11.788/2008 (BRASIL, 2008) dispõe sobre o estágio de estudantes. Seu artigo primeiro define: "estágio é o ato educativo supervisionado, desenvolvido no ambiente de trabalho, que visa à preparação para o trabalho produtivo de educandos que estejam frequentando o ensino regular em instituições superiores" (BRASIL, 2008). Além disso, o parágrafo um desse mesmo artigo salienta que "o estágio faz parte do projeto pedagógico do curso, além de integrar o itinerário formativo do educando".

Desse modo, a disciplina Estágio da Educação Infantil foi organizada mediante orientações do projeto pedagógico do curso de Pedagogia (PPC) ${ }^{6} \mathrm{da}$ UFT, câmpus Palmas, que tem o seguinte objetivo: "Garantir a aprendizagem

${ }^{6}$ O PPC do curso de Pedagogia está organizado mediante as diretrizes nacionais para o curso de graduação em Pedagogia (CONSELHO NACIONAL DE EDUCAÇÃO, 2006).

Rev. Fac. Educ. (Univ. do Estado de Mato Grosso), Vol. 28, Ano 15, № 2 p. 15-36, jul./dez. 2017 (Epub Ahead of Print 8. out., 2017) 
significativa dos conteúdos da formação educativa, vinculada à prática pedagógica problematizadora, teorizada e transformada a partir das investigações dos estagiários"(UNIVERSIDADE FEDERAL DO TOCANTINS, 2007, p. 28). A disciplina, que é normalmente garantida semestre a semestre, tem carga horária de 120 horas e é ministrada no sexto período do curso.

A partir dessas orientações adotou-se como eixo principal a pesquisa, ou seja, ela é o método de formação no estágio (PIMENTA; LIMA, 2004), pois acredita-se que a prática de ensino deve caminhar para a reflexão da realidade, visto que é uma atividade teórico-prática. É importante ater-se também para o conceito mais abrangente da identidade do professor no Brasil, para uma ideia de intelectual crítico e reflexivo (PIMENTA, 2008), visto que tal reflexão precisa levar em conta a influência do contato social e histórico; o professor deve ser permeado pelas tendências teóricas de sua época e, só assim, ter um potencial transformador em sua prática.

O esquema adotado para o desenvolvimento dessa disciplina buscou seguir as perspectivas do estágio como pesquisa - utilizando levantamento bibliográfico, observação participante, análise de documentos e entrevista por meio das seguintes atividades: diagnóstico (observação geral da escola e dos gestores e leitura de documentos como o projeto político-pedagógico), observação da ação docente (participação nas aulas e planejamento dos professores), escrita e desenvolvimento do projeto de pesquisa simultaneamente às regências. Todas essas atividades foram sendo realizadas no sentido de aproximar as conjunturas escolares, mergulhadas no contexto sócio-histórico e analisadas por teorias pertinentes a cada situação encontrada.

\section{Indicações de resistência: o que revela a pesquisa}

Esta investigação, que se destinou a compreender os rastros históricos e sociais da profissionalização de docentes para a primeira infância no Brasil, assim como os sinais de negação para uma possível atuação dos futuros pedagogos na educação infantil, tem como orientação metodológica a pesquisa qualitativa. Seguiram-se as indicações de Bogdan e Biklen (1994), que afirmam que as pesquisas de cunho qualitativo são descritivas e os dados são analisados de forma indutiva; os pesquisadores "tentam analisar os dados em toda a riqueza, respeitando, tanto o possível, a forma em que estes foram registrados ou transcritos" (BOGDAN; BIKLEN, 1994, p. 48).

Considerar a abordagem qualitativa significa caminhar no sentido de 
um estudo que se comprometa com o aprofundamento das análises a fim de valorizar as falas dos sujeitos e os processos sociais e históricos no qual estão inseridos. Dessa forma, segundo Bogdan e Biklen (1994), uma das principais características desse tipo de pesquisa é que ela considera o processo mais importante que o resultado.

Apesar do uso do questionário não ser comum em estudos dessa natureza, optou-se por utilizar esse instrumento para o registro de dados da avaliação dos alunos referente à disciplina Estágio da Educação Infantil e à sua autoavaliação no que tange a suas percepções sobre o impacto desse momento da formação. $\mathrm{O}$ uso de tal instrumento, juntamente com as notas da autora da pesquisa, também professora da disciplina, possibilitou a organização das informações ao longo de cinco semestres, a saber, 2011/II, 2012/II, 2013/I e 2014/I e II. Segundo Triviños (1987, p. 137), vários instrumentos de coleta de dados podem ser utilizados na pesquisa qualitativa, visto que esses dados "adquirem vida definida quando o pesquisador os ilumina com determinada teoria". Nessa lógica, "sem dúvida alguma, os questionários fechados [...], também o podemos usar na pesquisa qualitativa" (p. 137).

Ao longo dos cinco semestres da pesquisa, a disciplina Estágio da Educação Infantil teve um total de 110 alunos matriculados, dos quais $87^{7}$ participaram da pesquisa, o que significa que $79 \%$ dos estudantes responderam ao questionário. É interessante destacar o quantitativo de alunos e alunas matriculados no estágio, visto que as questões de gênero têm relevância nesta análise: dessa forma, havia 96 mulheres ( $87 \%$ do total) e 14 homens ( $13 \%$ do total).Entre os sujeitos da pesquisa, 78 são mulheres, o que corresponde a $90 \%$, e nove são homens, ou $10 \%$ do total. Com base nos estudos de Almeida (1998) e de Kramer (2011), constata-se que o maior número de matrículas efetuadas por mulheres no curso de Pedagogia perpetua a ideia de que a educação do público infantil continua circunscrita a esse gênero.

As perguntas do questionário foram: Como você chegou para fazer a disciplina de Estágio da Educação Infantil? Quais eram as expectativas? Foram sanadas? Diante da devolutiva dos alunos expressa em87 questionários, foi possível buscar as pistas direcionadas para a temática. As categorias foram criadas por meio do agrupamento das informações e da perscrutação das minúcias dos dados localizados, sem, contudo, perder de vista o todo desse processo, que vai além das vozes locais. A resposta de cada aluno pode ser classificada em várias categorias. Nesse sentido, foram criadas cinco categorias de análise:

1- Medo/dificuldade/preocupação/ansiedade: foi possível perceber,

${ }^{7}$ Para manter o sigilo dos participantes da pesquisa, foram usados nomes fictícios.

Rev. Fac. Educ. (Univ. do Estado de Mato Grosso), Vol. 28, Ano 15, № 2 p. 15-36, jul./dez. 2017 (Epub Ahead of Print 8. out., 2017) 
sobretudo nas respostas da primeira questão, que $41 \%$ dos acadêmicos utilizaram termos que indicam receio de realizar o estágio da educação infantil, o que permitiu formular esta categoria.

2- Conhecer o $\mathrm{CMEI}^{8} /$ preconceito/decepção/curiosidade/dúvida: em $21 \%$ das respostas da questão 1 surgiram indicativos referentes à pretensão dos alunos de sanar dúvidas sobre as escolas de educação infantil por meio do estágio; muitas dessas respostas, como se verá adiante, revelaram preconceitos sobre os fazeres nos CMEls.

3- Experiência importante/gratificante/aprendizado: estes termos, encontrados em $21 \%$ das respostas, foram fundamentais para construir esta categoria, que buscava saber se as expectativas dos estagiários foram sanadas.

4- Entender a educação infantil/educar/cuidar: a formulação desta categoria deu-se por meio das respostas da questão 2 sobre quais eram as expectativas em relação ao estágio, e $9 \%$ dos acadêmicos evidenciaram que queriam compreender a educação infantil.

5- Professor encontrado no CMEl: as três questões ajudaram a verificar os comentários dos alunos em relação aos professores, por isso $8 \%$ das respostas mencionavam esses profissionais atuantes nas escolas de estágio.

A primeira categoria - Medo/dificuldade/preocupação/ansiedade - esteve presente em $41 \%$ do total das respostas. Esse quantitativo bastante expressivo mostra a resistência dos alunos em relação a estagiar em escolas infantis. Percebeu-se que chegaram à graduação com preconceitos sobre os fazeres na primeira etapa, isto é, estariam em uma instituição onde as atividades do professor - como cuidar (dar banho, trocar fraldas...) - são desvalorizadas (KRAMER, 2008), o que é um despropósito, no imaginário social, para um profissional de nível superior. Tem-se as seguintes falas:

Tinha muito interesse de fazer o estágio na Educação Infantil, pois tinha a curiosidade de conhecer a realidade dos CMEls de Palmas e participar de perto do processo de formação/aprendizagem das crianças. Confesso que a realidade encontrada superou minhas expectativas porque tive a oportunidade de estagiar em um CMEl organizado, funcionários que nos acolheram bem. E o principal: atuar como professora. (Luana) ${ }^{9}$

No início da disciplina estava um pouco apreensiva por não saber o que poderia encontrar mas ao mesmo tempo, imaginava não ser nada tão complicado. Minha expectativa era tirar de letra,

${ }^{8}$ Centro Municipal de Educação Infantil.

${ }^{9}$ Para preservar a identidade dos participantes da pesquisa, foram usados nomes fictícios.

Rev. Fac. Educ. (Univ. do Estado de Mato Grosso), Vol. 28, Ano 15, № 2 p. 15-36, jul./dez. 2017 (Epub Ahead of Print 8. out., 2017) 
porém vi que a profissão de professor da Educação Infantil não se resume a apenas cuidar de crianças, abrange algo bem maior. Necessita de muito planejamento para não perder o controle. (Alice)

O depoimento de Luana deixa claro que ela foi surpreendida com a organização da escola de educação infantil do estágio, isto é, sua expectativa era encontrar um lugar desleixado, o que é um indício da relutância diante de uma instituição desvalorizada socialmente (SILVA, 2001). Outro ponto interessante da fala dessa aluna é que lhe foi possível ser professora nesse espaço, ou seja, é provável que ela tivesse em mente que o estágio se resumiria a atividades de cuidadora de bebês e crianças pequenas, e que não fariam parte do processo momentos destinados aos fazeres "próprios"de professora; contudo, essa expectativa também foi superada.

Alice, por sua vez, tinha construída a ideia de que é muito fácil ser docente na educação infantil: basta cuidar. Esta ideia foi construída historicamente (KUHLMANN, 2003, OLIVEIRA, 2002). Fica claro o movimento de reação da aluna, pois certamente não acreditava que precisasse fazer faculdade para tutelar bebês em creches. Entretanto, ela pode mudar essa concepção ao perceber que existe planejamento na instituição que lida com crianças pequenas, que o professor tem de estudar para conseguir avançar no dia a dia da escola, tem de registrar sua prática (que deve ser intencional) e o desenvolvimento de cada criança - enfim, é um trabalho difícil, a ser realizado por gente qualificada. É fundamental que este país priorize a educação para que a política de formação de professores de educação infantil possa ser levada a sério. Para Didonet (2014), a complexidade da instrução da criança exige especialistas no assunto, ou seja, professores altamente preparados.

No que se refere à segunda e quarta categorias - Conhecer o CMEI/ preconceito/decepção/curiosidade/dúvida ( $21 \%$ de respostas) e Entender a educação infantil/educar/cuidar ( $9 \%$ de respostas) -, pode-se dizer que a construção/compreensão da função da educação infantil constitui um processo intrincado e que o conceito de educar/cuidar ainda carece de lapidação no contexto brasileiro (CERISARA, 2004; KRAMER, 2008). Além disso, é preciso situar os conceitos de criança e de infância, compreendendo que estes são tecidos na sociedade a partir dos arranjos sócio-históricos intimamente ligados à lógica econômica e política. Uma vez que existem diversas infâncias, as quais, por sua vez, especificam-se nos espaços regionais e locais, são "múltiplos os tempos de infância e nele coexistem realidades e representações diversas" 
(CORSINO, 2012, p. 15), mas a sociedade globalizada cria aspectos universais sobre a infância e a criança. A disciplina de estágio também teve a intenção de revisitar os referidos conceitos, pois eles agem de modo decisivo na construção da identidade do profissional. Seguem dois depoimentos:

Tive muita ansiedade quando comecei a disciplina de estágio infantil pois, não sabia se conseguiria trabalhar com crianças pequenas. Não sabia como seria a relação estagiária e bebê, mas assim que tive a primeira experiência na creche, que foi justamente no berçário, percebi que era capaz de atuar como professora em uma creche. Superei as expectativas. (Júlia)

Ao iniciar o estágio tive de início uma visão equivocada do que consistia em estagiar no CMEI. Como nunca havia estado numa sala, achei que era apenas uma professora para 45 alunos e que não havia dinâmica nem momento de ensino em sala. Depois de um período de observação minha visão mudou, com relação ao desenvolvimento das aulas, as crianças participaram e colaboraram para que o mesmo ocorresse da melhor forma possível. (Eva)

O comentário de Júlia sugere grande relutância em lidar com bebês na instituição de educação infantil. É curioso que ainda persiste a ideia de que atuar na creche é menos importante que na pré-escola e nos demais ambientes da educação básica (DIDONET, 2014). Apesar do prejulgamento, a aluna diz ter sido significativo o contato com os bebês e que construiu conhecimentos no sentido de superar as expectativas iniciais. Já a fala de Eva mostra um lado bastante negativo de muitas escolas de educação infantil: a superlotação. A concepção da aluna no que se refere a creches, bem como de muitas pessoas na sociedade em geral, é a de um depósito de crianças para os pais poderem ir trabalhar. Mas essa visão também mudou quando Eva percebeu que havia muitos profissionais envolvidos em cada turma e que as atividades pedagógicas eram possíveis.

A terceira categoria - Experiência importante/gratificante/aprendizado - esteve presente na resposta de $21 \%$ dos participantes, revelando uma avaliação positiva em relação à disciplina Estágio da Educação Infantil. Foi oportuno concluir que as atividades propostas por meio da metodologia do estágio (PIMENTA E LIMA, 2004), tendo como eixo orientador a pesquisa, renderam frutos valorosos, pois a lógica social de desvalorização do profissional da educação infantil e dos seus fazeres nas instituições de ensino cedeu lugar 
a novos entendimentos que prezam esse profissional e concebem sua ação como altamente complexa e notável.

Cheguei à disciplina com um pouco de ansiedade para conhecer o CMEl e como acontece o trabalho nele. Logo no início, quando trabalhamos os textos, tive um pouco de medo porque houve a quebra de conceitos já construídos, pois comecei a ver que a Educação Infantil não é fácil no sentido de que não pode ser assistencialista, nem pode introduzir o ensino fundamental para as crianças. Com o passar do tempo o medo foi passando, começamos a ter contato com a escola. (Marta)

Quando desenvolvi a pesquisa foi muito prazeroso, uma sensação única. Tinha a ideia de que na Educação Infantil só se cuidava e educava pouco. Com as regências percebi que para trabalhar na Educação Infantil tem de estudar muito. (Ana)

Apesar de o estágio ter permitido aos alunos o encontro com muitas situações positivas e interessantes na ação docente e na prática institucionalizada, possibilitou-lhes também o enfrentamento de realidades complicadas em diversos sentidos, que colocaram em destaque a atuação dos professores. A quinta categoria - Professor encontrado no $\mathrm{CMEI}-$, com $8 \%$ dos comentários, revela um quadro triste:

Eu cheguei para fazer a disciplina de estágio um pouco apreensiva, mas também muito curiosa para entender como funciona a prática do profissional docente. Minhas expectativas eram de encontrar professores totalmente preparados para estar à frente da educação de nossas crianças, mas não foram os profissionais que eu esperava encontrar. (Vera)

Conhecer de fato como funciona a Educação Infantil era meu objetivo mas fiquei frustrada pois existe uma rotina engessada, sem sentido para as crianças e os professores, não todos mas a maioria, são infelizes, não trabalham como deveriam, são grossos com as crianças, não desenvolvem algo pedagógico, cantam o tempo todo, não tem muito conhecimento de seu fazer pedagógico. O que é uma pena. Ficaram muitas perguntas sem respostas e a que mais me inquieta é: para que uma rotina maçante? (Aline) 
Os alunos depararam-se com profissionais pouco preparados, desmotivados pelas condições de trabalho e convencidos de que o que fazem não tem valia. Nesse contexto, $\operatorname{Kramer}(2008$, p. 81 ) destaca que toda criança "tem direito à educação infantil de qualidade, com professores que também sejam tratados, se vejam e atuem como sujeitos sociais"; contudo, o poder público e a sociedade carecem de uma ruptura de velhos conceitos no atendimento de crianças pequenas, assim como os alunos desta pesquisa, uma vez que, "em condições precárias, não se educa, nem se cuida", tampouco se faz o educar/ cuidar de forma integrada. As declarações de Vera e Aline revelam a decepção com os professores que encontraram no estágio e a desmotivação perante seu processo de formação que as levará, no futuro, a trabalhar em instituições de educação infantil.

\section{Considerações finais}

A presente investigação buscou problematizar a história da profissionalização do docente da educação infantil no Brasil, situando a origem desse trabalho em fazeres femininos expropriados de intencionalidade profissional. A pesquisa também abordou as políticas de formação e as diversas instituições que foram, ao longo do tempo, se responsabilizando pela capacitação do profissional da educação básica, o que inclui o professor da primeira etapa. Sabe-se que no tempo presente o curso de Pedagogia tem limitações significativas na formação de seus profissionais, mas o fato de a preparação de docentes da educação infantil e das séries iniciais do ensino fundamental estar vinculada a esse curso de licenciatura em nível superior é, sem dúvida, um ganho definitivo.

Uma questão irrefutável é que a formação de pessoas para atuar em creches e pré-escolas requer especificidades. Para Oliveira-Formosinho (2011), o conceito de educar/cuidar dá uma dimensão diferente e mais ampla para o trabalho realizado pelo professor, o que exige uma capacitação que dê conta do caráter integralizado das ações, oportunizando, nesse sentido, o desenvolvimento de um bom serviço prestado às crianças.

Apesar das mudanças ocorridas nas duas décadas que sucederam à promulgação da atual LDB e outros dispositivos legais, percebe-se que há ainda muito por fazer em termos de formação, posto que boa parte das pessoas que assumem trabalho em creches ou pré-escolas não têm qualificação. Além disso, o cenário educacional brasileiro carece de rupturas e ressignificações sobre a construção da identidade e da valorização do professor de educação infantil (CERISARA, 2004; DIDONET, 2014; KRAMER, 2011; SILVA, 2001). 
Numa lógica contraditória vive-se o sequente desprestígio de professores. Isso é sentido no curso de Pedagogia da UFT/Palmas, que, por meio da disciplina Estágio da Educação Infantil, busca contribuir com a formação do docente da primeira infância. Por meio de seus depoimentos, os sujeitos da pesquisa mostraram palpáveis sinais de resistência em se tornarem docentes desse segmento da educação em virtude da construção sócio-histórica do perfil desse profissional; ou seja, para cuidar e brincar com bebês, crianças bem pequenas e crianças pequenas, não é necessário ter diploma de ensino superior. Tal conceito afasta da educação infantil o interesse dos futuros professores.

Assim, urge que haja quebras nas ideologias que ainda hoje constituem a identidade do professorado infantil, por meio de políticas mais eficazes de formação, valorização salarial e melhores condições diárias de trabalho. A dignidade do docente das instituições de educação infantil garantirá que as crianças também tenham uma educação de qualidade.

\section{Referências}

ALMEIDA, J. S. Mulher e educação: a paixão pelo possível. São Paulo: Ed. Unesp, 1998.

ARAÚJO, D.S. Infância, família e creche: um estudo dos significados atribuídos por pais e educadoras de uma instituição filantrópica. 2006. 265 f. Tese de doutorado. Universidade Federal de Goiás. Goiânia, 2006.

BENJAMIN. W. Magia e técnica, arte e política: ensaios sobre literatura e história da cultura. Tradução de Sérgio Paulo Rouanet. 3. ed. São Paulo: Brasiliense, 1987. v. 1. (Obras Escolhidas).

BARBOSA, I.G. O Proinfantil e a formação de professores. Revista Retratos da Escola/ Escola de Formação da Confederação Nacional dos trabalhadores em Educação (Esforce). Brasília, V.05, n 09, jul/dez, 2011. p.385-399.

BOGDAN, R.; BIKLEN, S. Investigação qualitativa em educação: uma introdução à teoria e aos métodos. Tradução de Maria João Alves et al. Porto: Porto Editora, 1994.

BRASIL. Lei no 5.692, de 11 de agosto de 1971. Fixa diretrizes e bases para o ensino de 10 e 20 graus, e dá outras providências. Diário Oficial da União, Brasília, DF, 12 ago. 1971.

BRASIL. Lei $n^{\circ} 8.069$, de 13 de julho de 1990. Dispõe sobre o Estatuto da 
Criança e do Adolescente e dá outras providências. Diário Oficial da União, Brasília, DF, 16 jul. 1990.

BRASIL. Lei no 9.394, de 20 de dezembro de 1996. Estabelece as diretrizes e bases da educação nacional. Diário Oficial da União, Brasília, DF, 23 dez. 1996.

BRASIL. Lei no 11.788, de 25 de setembro de 2008. Dispõe sobre o estágio de estudantes [...] e dá outras providências. Diário Oficial da União, Brasília, DF, 26 dez. 2008.

CERISARA, A. B. Por uma pedagogia da Educação Infantil: desafios e perspectivas para as professoras. In: BARBOSA, R. L. L. (Org.). Trajetórias e perspectivas da formação de educadores. São Paulo: Ed. Unesp, 2004. p. 347-356.

CONSELHO NACIONAL DE EDUCAÇÃO (CNE). Resolução CNE/CP $n^{\circ} 1$, de 15 de maio de 2006. Institui Diretrizes Curriculares Nacionais para o Curso de Graduação em Pedagogia, licenciatura. Diário Oficial da União, Brasília, DF, 16 maio 2006. Seção 1, p. 11.

CONSELHO NACIONAL DE EDUCAÇÃO (CNE). Resolução $n^{\circ} 2$, de $1^{\circ}$ de julho de 2015. Define as Diretrizes Curriculares Nacionais para a formação inicial em nível superior (cursos de licenciatura, cursos de formação pedagógica para graduados e cursos de segunda licenciatura) e para a formação continuada. Diário Oficial da União, Brasília, DF, 2 jul. 2015. Seção 1, p. 8-12.

CORSINO, P. (Org.). Educação infantil: cotidiano e políticas. São Paulo: Autores Associados, 2012.

CURY, C. R. J. Sentidos da educação na Constituição Federal de 1988. Revista Brasileira de Política e Administração da Educação, Goiânia, v. 29, n. 2, p. 195-206, 2013.

DIDONET, V. A educação infantil na LDB/1996: mudanças depois de 2007. In: BRZEZINSKI, I. (Org.). LDB/1996 contemporânea: contradições, tensões, compromissos. São Paulo: Cortez, 2014. p. 144-170.

DRUMONT, V. Formação de professores e professoras de Educação Infantil no Curso de Pedagogia: estágio e pesquisa. Tese de doutorado. 216 f. Universidade Estadual de campinas. Campinas, 2014.

DOURADO, L. F. Formação de profissionais do magistério da Educação Básica: novas diretrizes e perspectivas. Comunicação \& Educação, São Paulo, Ano XX, n. 1, p. 27-39, jan./jun. 2016.

KISHIMOTO, T. M. Encontros e desencontros na formação dos profissionais da 
educação infantil. In: MACHADO, M. L. (Org.). Encontros e desencontros em Educação Infantil. 4. ed. São Paulo: Cortez, 2011. p. 107-115.

KUHLMANN, M. Educando a infância brasileira. In: LOPES, E. M. T.; FARIA FILHO, L. M.; VEIGA, C. G. (Org.). 500 anos de educação no Brasil. 3. ed. Belo Horizonte: Autêntica, 2003. p. 469-496.

KUHLMANN, M. Infância e educação infantil: uma abordagem histórica. Porto Alegre: Mediação, 1998.

KRAMER, S. A política do pré-escolar no Brasil: a arte do disfarce. 5. ed. São Paulo: Cortez, 1995.

KRAMER, S. Direitos da criança e projeto político pedagógico de educação infantil. In: BASÍLIO, L. C.; KRAMER, S. (Org.). Infância, educação e direitos humanos. 3. ed. São Paulo: Cortez, 2008. p. 51-82.

KRAMER, S. Formação de profissionais de educação infantil: questões e tensões. In: MACHADO, M. L. (Org.). Encontros e desencontros em Educação Infantil. 4. ed. São Paulo: Cortez, 2011. p. 117-132.

LEITE FILHO, A. G.; NUNES, M. F. Direitos da criança à Educação Infantil: reflexões sobre a história e a política. In: KRAMER, S.; NUNES, M. F.; CARVALHO, M. C. (Org.). Educação infantil: formação e responsabilidade. Campinas: Papirus, 2013. p. 67-88.

MÉSZÁROS, I. A educação para além do capital. Tradução de T. Brito. Revista Theomai, Buenos Aires, n. 15, p. 107-130, 2007. Disponível em: <http://revista-theomai.unq.edu.ar/NUMERO15/ArtMeszaros_15.pdf $>$. Acesso em: 27 nov. 2016.

MICARELLO, H. Formação de professores da educação infantil: puxando os fios da história. In: ROCHA, E. A. C.; KRAMER, S. (Org.). Educação infantil: enfoques em diálogo. Campinas: Papirus, 2011. p. 211-228.

MINISTÉRIO DA EDUCAÇÃO E CULTURA (MEC). Secretaria de ensino de $1^{\circ} \mathrm{e}$ $2^{\circ}$ grau. Subsecretaria de Ensino Regular. Legislação e normas da educação pré-escolar. Brasília, DF, 1979.

MINISTÉRIO DA EDUCAÇÃO E CULTURA (MEC). Edição especial: Proinfantil em debate. Brasília, DF, Ano XX, Boletim 20, dez. 2010.

MINISTÉRIO DA EDUCAÇÃO E CULTURA (MEC); UNIVERSIDADE FEDERAL DO RIO GRANDE DO SUL (UFRGS). Práticas cotidianas na educação infantil: bases para a reflexão sobre as orientações curriculares. Brasília, DF, 2009. 
OLIVEIRA, Z. Os primeiros passos da história da Educação Infantil no Brasil. In: . Educação Infantil: fundamentos e métodos. São Paulo: Cortez, 2002. $\overline{\text { p. } 91-120 .}$

OLIVEIRA-FORMOSINHO, J. O desenvolvimento profissional das educadoras de infância: entre os saberes e os afectos, entre a sala de aula e o mundo. In: MACHADO, M. L. (Org.). Encontros e desencontros em Educação Infantil. 4. ed. São Paulo: Cortez, 2011. p. 133-198.

OSTETO, L. E. Andando por creches e pré-escolas públicas: construindo uma proposta de estágio. In: . (Org.). Encontros e encantamentos na educação infantil. Campinas: Papirus, 2000. p. 15-30.

PIMENTA, S. G. Professor reflexivo: construindo uma crítica. In: PIMENTA, S. G.; GHEDIN, E. Professor reflexivo no Brasil: gênese e crítica de um conceito. 5. ed. São Paulo: Cortez, 2008. p. 17-52.

PIMENTA, S. G.; LIMA, M. S. L. (Org.). Estágio e docência. São Paulo: Cortez, 2004.

SAVIANI, D. Formação de professores: aspectos históricos e teóricos do problema no contexto brasileiro. Revista Brasileira de Educação, Rio de Janeiro, v. 14, n. 40, p. 143-155, jan./abr. 2009. Disponível em: <http://www.scielo.br/ pdf/rbedu/v14n40/v14n40a12.pdf>. Acesso em: 30 nov. 2016.

SILVA, I. O. Profissionais da educação infantil: formação e construção de identidade. São Paulo: Cortez, 2001.

SILVEIRA, T.A.T. M, Práticas pedagógicas na educação de crianças de zero a três anos de idade: concepções acadêmicas e de profissionais de educação. Tese de doutorado. 304 f. Universidade Federal de Goiás-UFG. Goiânia, 2015.

TRIVIÑOS, A. N. S. Introdução à pesquisa em ciências sociais: a pesquisa qualitativa em educação. São Paulo: Atlas, 1987.

UNIVERSIDADE FEDERAL DO TOCANTINS. Projeto Político-Pedagógico do curso de Pedagogia do Campus de Palmas. Palmas, abr. 2007.

VALENTE, L. F. Políticas de formação de professores no Brasil nos anos 2000: desafios e possibilidades. In: BORGES, M. C.; AQUINO, O. F. (Org.). A formação de professores para a educação básica: discussões teóricas e práticas. Uberlândia: Edufu, 2015. p. 29-60.

Data de recebimento: 02.03.2017

Data de aceite: 29.05.2017 